[Accepted article - not to be reproduced without consent of the author]

\title{
Social Work Expertise, Best Interests and the Court of Protection
}

Jaime Lindsey and Mary O’Reardon

\section{Structured Abstract}

Purpose: The purpose of this article is to consider the role of social work professional evidence in mental capacity law, specifically Court of Protection proceedings. We analyse how social workers perform as evidence givers in this domain and how social work as a profession is perceived alongside other professions within the context of adult social care decision-making in mental capacity law.

Design/methodology/approach: The paper draws on textual evidence from judgments and existing empirical data published elsewhere. We consider the contribution of social work professional expertise to best interests decision making in formal legal proceedings which, in turn, reflects on how social work expertise is relevant in everyday practice.

Findings: The findings of this paper include that social workers are well placed to be experts on best interests decision-making in mental capacity law. However, we show that the Court of Protection has not always endorsed this form of social work expertise in its judgments, meaning that social workers can struggle to articulate an expert knowledge base.

Originality: Overall, we conclude that social work evidence is incredibly valuable as expertise about the person's best interests, particularly in the domain of welfare cases and care planning.

\section{Introduction}

Participation in court proceedings is not an everyday event for most social workers. A 2015 survey by trade union 'Unison' reported that almost half of social work respondents $(49 \%)$ felt they lacked confidence in relation to court proceedings and would feel unduly anxious about having to participate 
at this level. A further $90 \%$ of respondents commented that the pressure of daily tasks prohibited them from having sufficient time to prepare court reports appropriately and to upskill in this area (Unison, 2015). However, communication of specialised opinion is central to the role of professionals and this requires knowledge of relevant legal and policy frameworks within which the social worker operates. In the context of adult protection, one of the most important legal frameworks that social workers in England and Wales need to understand and engage with is the Mental Capacity Act 2005 (MCA).

The MCA created the 'Court of Protection' (CoP) in the form that we see today operating in England and Wales, although it existed prior to the MCA, primarily dealing with property and affairs issues (Weston, 2020). The CoP is a specialist court that was established to consider cases of health, welfare or property and financial affairs where there is reason to suspect that the person lacks the mental capacity to make the decision in question. Where a person is found to lack the mental capacity to make a decision, the CoP can make certain decisions on that person's behalf if it is in their best interests. ${ }^{1}$ However, in everyday settings, social workers and other health and social care professionals will often make best interests decisions routinely for their service users and people in their care. For example, everyday best interests decisions might be taken about what activities the person should undertake, what food they should be offered or who they can have contact with. It is not always necessary for these types of best interests decisions to go before the CoP, because s 5 MCA provides an important defence to people who, in connection with care or treatment, and have taken reasonable steps to establish capacity, reasonably believe that the person lacks capacity and that they are acting in the person's best interests. For this reason, it is important that social workers have a good understanding of mental capacity law and its application in everyday settings.

\footnotetext{
${ }^{1}$ S 4 MCA.
} 
Where cases do reach the CoP, the court has the authority to instruct agencies to empower and support decision making, the power to deem that an individual lacks capacity in relation to a particular decision, and the authority to be the substitute decision maker for that individual. While the majority of court approved decisions are managed on paper and without an oral hearing (Brammer, 2012), the CoP's workload has seen a major increase in recent years (Ministry of Justice, 2020), with applications now routinely heard across England and Wales for decisions relating to as wide a range of issues as where the person should live, what contact they should have with friends and family, what care they should be provided with and what medical treatment they ought to be given. Many of these decisions are engaged in every day social work practice, making it essential that social workers understand the legal framework of the MCA and their appropriate role within it.

CoP proceedings provide an opportunity to analyse how social workers perform as evidence givers, and furthermore, how social work as a profession is perceived alongside other professions within the context of adult social care decision-making. In this regard, this paper focuses on the use of social work evidence in the CoP, drawing on evidence from CoP judgments and existing empirical data about the CoP. This paper considers the contribution of social work to best interests decision-making in formal proceedings which, in turn, reflects on how social work expertise is relevant in everyday practice. We suggest that the CoP has not always endorsed social work as a form of expertise, meaning that social workers can struggle to articulate an expert knowledge base. We recognise that social work expertise will not be relevant to all decisions made under the MCA or in every CoP case. However, we argue that social workers are, in many instances, well placed to be experts on best interests decisionmaking, particularly in relation to everyday welfare decisions and care planning.

\section{Social Work Expertise}


From its enactment in 2005, the MCA's notable potential for empowering social workers and social work service users was positively received by stakeholders (Manthorpe et al., 2009). The ethos of the MCA was based on empowerment and protection, ensuring that services users with capacity are free to make their own decisions and those who lack capacity in particular domains are protected. In practice, however, the implementation of the MCA has been challenging at times. For example, some have argued that the empowerment ethos has been lost in favour of protectionism (Dunn, Clare and Holland, 2008; Hollomotz, 2011; Clough, 2018). It has also been argued that professionals need to genuinely engage with ways to empower disabled people to make decisions in their own lives (Harding and Taşcıoğlu, 2020) and social work, in particular, is well placed to do this given that their legitimacy stems from their relationship of support with service users (Lindsey, Forthcoming).

Social work 'expertise' often gathers media attention in tragic circumstances when human suffering is exposed. An inquiry following a serious incident or a death that was deemed to be preventable will often be reported in the media, particularly if there is a concurrent criminal trial, for example the murder of Stephen Hoskin (2007) and the profound neglect and abuse causing the death of a child Victoria Climbié (2009). In some instances, a high-profile inquiry will prompt a government led review of health and social care practices more widely. For example, the Laming Review (2009) and the Winterbourne View Inquiry (2012) following the BBC expose of routine abuse and neglect of adults residing in a designated Learning Disability Assessment Unit. Each of these inquiries brought considerable media spotlight on social work and critical research demonstrates evidence of a dismissive rhetoric towards social work as a profession (Jones, 2014; Shoesmith, 2016). Shoesmith (2016) argues that a recurrent emphasis on 'incompetence' developed a narrative that social workers are blind-sighted by collusion with the 'under-class', and that social work tasks would be better conducted by non-social work personnel who would make rational and therefore better decisions (Jones, 2014; Shoesmith, 2016). In the context of our research focus, mental capacity law and adult protection, this 'incompetence' narrative is perhaps best contrasted with the narrative of the medical 
expert, where 'doctor knows best' and law's deference to the medical profession is well documented (Lindsey, 2020). While there has been a tendency in some arenas to see mental capacity law as a strata of 'medical law', actually many mental capacity disputes involve social care provision by local authorities and social workers are often engaging with questions of capacity in their everyday roles (Keeling, 2017). This means that social workers are regularly used as the basis upon which to make an application to the CoP, particularly in welfare cases or cases that have a care planning or safeguarding element. However, they are much less commonly used as court appointed independent experts in CoP proceedings, even where the case raises adult protection issues. It has been argued that this is because social workers struggle to fit the narrative of the objective medical expert, instead being viewed as a more subjective form of knowledge, thereby undermining their claim to expertise (Lindsey, 2020). In this article, we continue this argument to claim that social workers are particularly well placed to be instructed as experts on best interests in CoP proceedings, highlighting the ways in which their evidence can be effective and represent good practice for a CoP expert, within the range of their training and responsibilities.

By way of further context, the emerging library of Safeguarding Adults Reviews (SARs) has the potential to become a health and social care practice resource to assist understanding and learning at the intersection of mental capacity and adult protection. They also represent an insight into the daily delivery of often highly complex multi-disciplinary support and care interventions for adults at risk of harm, which in turn highlight the expertise of social workers operating within these areas. SARs are a unique artefact, however, it is important to highlight that they represent the examples of instances when harm or abuse was not prevented which is far from the everyday reality of effective social work practice. This paper is mindful that to call on SARs for evidence might contribute to bad news of abuse and harm being a dominant narrative about social work; a concern explored previously by social work researchers (Cooper and Lousada, 2005; Shoesmith, 2016; Kettle, 2018). In 2017, the Association of Directors of Adult Social Services (ADASS) commissioned a London-wide review of SARs. The report 
highlighted that implementation of the MCA presented considerable challenges to the involved professionals including social workers, evidencing limited authentic adherence to MCA (Braye and Preston-Shoot, 2017). In 2020 the Local Government Association published the first widespread review of SARs including over 260 reports published between April 2017 and March 2019. This review highlighted notable instances of good practice with regard to 'attention to mental capacity' with several examples of joint working, appropriate consideration of capacity and robust best interests decisions (Preston-Shoot et al, 2020, 84). However, the report also indicated that 'attention to mental capacity was one of the most frequent deficiencies in direct practice ... with concerns about how assessment, best interests and deprivation of liberty were addressed' (Preston-Shoot et al, 2020, 118).

The challenge for practitioners of working with other disciplines with each interpreting the MCA through the lens of their professional priorities could lead to many areas of conflict and disagreement about best interests. Choosing just one recent example, this phenomenon was noted in a SAR in relation to MS who passed away at a bus stop where he had been sleeping for several nights. The SAR reported that practitioners struggled to reach across their service areas and to challenge each other's assessments of capacity, and particularly to challenge whether that assessment was specific to the decision at hand (Preston-Shoot, 2021). The competing priorities of each professional focus while assessing capacity has been explored by Kong and Ruck Keene (2018) using case studies to illustrate the levels of complexity and competing ethical demands that can arise (Kong and Ruck Keene, 2018). For Kong and Ruck Keene, given that assessments of capacity are most often driven by a desire to offer care and support to an individual, or perhaps even to seek to control an individual's movements, assessments of capacity are, in their view, inherently ethical and value driven.

At first glance, given that the social work profession's core values include advocacy, empowerment and holistic assessment, the MCA should be a natural fit with social work expertise (BASW,2014). Specific research on this issue with social workers in practice reported that practitioners interpret the 
MCA with clarity, however, the execution of assessments and best interest decisions tends to become integrated into other processes - suggesting concerns about the objectivity of these assessments (Murrell \& McCalla, 2015). Does it actually fit with the daily tasks of a social worker to be both assessor, decision-maker and service provider? Offering a series of predominantly social care casestudies and evidence from court judgments, Kong and Ruck Keene (2018) challenge the efficacy of the MCA in action, reinforcing the SARs analysis above. They point to contradictions, competing narratives and scenarios that seem to fall outside of the obvious guidelines suggesting that the MCA itself is not fit for everyday purpose (Kong and Ruck Keene, 2018). However, in spite of these challenges, the evidence from the CoP that we present here suggests notably high levels of professional competence for social work, and in a context of complexity and conflict. This makes social workers well placed as evidence givers and experts in CoP proceedings, particularly for best interests disputes within their domain of practice.

\section{Evidence in the Court of Protection}

An application to the CoP requires evidence in support (COP1 for most matters and COP DLA for DOLS). This means that where a local authority is submitting an application in relation to a person they believe lacks the mental capacity to make the decision, they will need to refer to the evidence upon which they rely to substantiate that belief. In addition to general information about the decision and the person to whom it relates, the COP3 form used to support most applications in this area includes a section which states:

Please provide any further information about the circumstances of the person to whom the application relates that would be useful to the practitioner in assessing his or her capacity to make any decision(s) that is the subject of your application. 
For the social worker completing a COP3, then, the task is to provide a basis for the local authority's opinion that the person lacks the mental capacity to make the decision. In practice, COP3 forms are often poorly completed and provide very little by way of justification, sometimes being seen as a tick box exercise (Series et al., 2015). Of course, many social workers carry out a full assessment of their client's mental capacity and best interests routinely. The criticism, though, is that this does not always translate to robust evidence before the CoP. The social worker therefore carries out a somewhat hybrid role in CoP proceedings. If their evidence has been used on the COP3 application, then the court may decide this is sufficient evidence to make a decision on capacity. However, in some instances, the court may question the quality of the professional assessment or the actions taken by an agency such as a local authority prior to the court hearing. In these more complex or contested cases the court may also appoint an independent expert to provide an opinion.

The role of this independent expert is, according to the Court of Protection Rules 2017 (COPR), to provide 'objective, unbiased opinion on matters within the expert's field of expertise, and should not assume the role of an advocate'. As Lindsey has argued, '[t]here is no detail on which types of expert should be used, but case law suggests that there is no requirement for a capacity assessment to be carried out by a person with psychiatric or other specific medical expertise' (Lindsey, 2020, 4). In relation to mental capacity, then, any expert with relevant knowledge or expertise, usually relating to the person's condition, can be appointed to assist the court to resolve any issues.

While social workers are sometimes appointed as independent experts, it is much more common for those with psychiatry or clinical psychology expertise to be appointed, despite criticisms of this approach (Lindsey, 2020). While we recognise that social workers may not be the most appropriate 'expert' on issues of diagnosis of mental disorder, we argue that social workers are well placed to be instructed as independent experts on best interests decision-making, particularly in welfare cases. However, one difficulty with this distinction between experts on capacity and best interests is where 
this reliance on medical expertise exists despite the necessary best interests decision-making being outside of medical expertise and falling better within social work expertise. For example, in some cases the medical expert's opinion in relation to P's capacity was followed but the court then sought assurances from the social work experts in relation to care-plans and safeguarding. ${ }^{2}$ In these instances, the functional test of capacity is conducted by one professional and the practical execution of care planning (i.e. the bests interests question) by another. This could be seen to conflict with the MCA Code of Practice, which sets out that 'the person who assesses an individual's capacity to make a decision will usually be the person who is directly concerned with the individual at the time the decision needs to be made' (Department for Constitutional Affairs, 2007, para 4.38). If, however, mental incapacity is established, the court may then order further independent expert evidence relating to the best interests question. In the following section we argue that this is where social work expertise has the most potential and represents good practice with which social workers ought to become familiar.

Social work evidence on best interests

When an individual has been found to lack capacity in relation to a particular decision under the MCA, then, under s 1(5) MCA, any decision taken on behalf of that person must be taken in their best interests. The factors to be taken into account are set out in s 4 MCA, which focuses heavily on the person's own wishes and feelings as well as those close to them. A best interests decision should take into account any available knowledge of the individuals' preferences, along with any views they may have held prior to the loss of capacity. Crucially, a best interests decision is to be understood as a decision that is in the best interests of the assessed individual rather than a course of action that is the preference or better interests of those supporting them. Focusing on this aspect of the MCA

\footnotetext{
${ }^{2}$ Re P [2017] EWCOP B26; Re HH [2018] EWCOP 13; Buckinghamshire County Council v RT [2018] EWCOP B12.
} 
framework, we show here that social workers have had some success in recognition of their professional expertise in relation to best interests decisions compared to in relation to judgments about mental capacity. Furthermore, we suggest that this represents a positive model for social work evidence before the CoP.

Turning to our analysis of reported CoP judgments next, we read and analysed reported CoP case law publicly available on the British and Irish Legal Information Institute (BAILII) for cases that refer to or include reference to social work evidence. From our analysis, we have identified key examples of cases where social work evidence was referred to by the judge, notwithstanding the known weaknesses of relying on reported judgments alone in this area (Lindsey, 2020). The first case is London Borough of Brent $v N B,{ }^{3}$ which concerned capacity to make a decision about accommodation, the case involved a young man whose care team deemed him appropriate for a residential rehabilitation placement. However, the family rejected this placement stating that NB did not wish to leave home and therefore residential rehabilitation would not be in his best interests. After a finding of incapacity in line with the evidence of the expert clinical psychologist, the court ordered an independent social worker to engage with NB and to seek to establish what was in his best interests, with the judgment noting that she was 'an independent social worker with 13 years of experience of care management within both the public and private sector'. ${ }^{4}$ The judge discussed the social work evidence at length, which was clearly and carefully presented with a focus on NB's own needs. The case represents a good example of how and when an independent social work expert might be appointed in a welfare case before the CoP and the effective ways in which social workers may source their evidence for the court. The way in which the social worker in this case developed and maintained a working relationship with NB over a period of time ought to be celebrated as a positive example of good practice in this arena.

\footnotetext{
3 [2017] EWCOP 34.

${ }^{4}$ Para 116.
} 
In another case, $F X^{5}$ the court similarly ruled in line with the social work evidence, even though this assessment conflicted with the opinions provided by others in the case, including a Consultant Psychiatrist. In this case the judge reported on both professionals' methods of analysing capacity and celebrated the social worker's methods noting: ${ }^{6}$

SN met FX on three occasions and was able form a better relationship with FX. Indeed, when I met with FX he told me "I know S, I opened up to her"

Bell J noted the particular credentials of the psychiatrist, noting his expertise in the field but suggesting that his higher level of knowledge of P's condition (Prada Willi Syndrome) may have led him to:?

conflate best interests capacity ... he acknowledged that with respect to understanding of relevant information he had set the bar quite high and linked this to the consequences of uncontrolled symptoms of PWS upon sufferers.

In contrast, the judge explained that the social worker: ${ }^{8}$

... takes a different view. She has different qualifications to those of Professor Holland and her assessment was not ordered for the purposes of these proceedings. However, she had the advantage of being able to meet more extensively with FX and was able to have more productive discussions with him. She conducted her assessment from the correct starting point of presuming that FX has capacity and applying the relevant statutory framework and guidelines.

\footnotetext{
${ }^{5}$ [2017] EWCOP 36

${ }^{6}$ Para 35.

7 Para 43.

8 Para 46.
} 
While these are examples of good practice in the use of social work evidence for best interests decision-making and examples of where such evidence has been well received by the CoP, there are also examples where the CoP has not adduced social work evidence where, we suggest, it would have been appropriate to do so. A topical example of a best interests decision that ought to have engaged social work evidence relates to the administration of the Covid 19 vaccine to a woman in her early seventies living in a care home with Korsakoff's syndrome. In SD v Royal Borough of Kensington and Chelsea ${ }^{9}$ an application was brought to the CoP by SD, on the basis that it was not in her mother, V's, best interests to receive the Covid-19 vaccine. The local authority opposed the application, arguing that it was in her best interests to receive the vaccine. Hayden J held that it was in V's best interests to receive the vaccine, despite her daughter's objections. SD was concerned about the efficacy and safety of the vaccine rather than opposing vaccines in their entirety. The local authority in this case focused heavily on medical concepts and expertise, submitting that the key factors included: ${ }^{10}$

i) Whether V is offered the Pfizer/BioNTech or the Oxford-AstraZeneca vaccine, both have been rigorously tested and are fully approved for use by the Medicines and Healthcare products Regulatory Authority ("MHRA"). Addressing one of SD's objections, it is pointed out that there have been sufficient clinical trials to meet the required safety, quality and effectiveness standards;

ii) The minimal risk identified, of any common side effects, was taken into account by V's GP, when making the recommendation that it would be in her best interests to receive the vaccine;

iii) As a resident in a care home, where all those being looked after are suffering from Korsakoff's syndrome and varying degrees of dementia, V's remains both at

\footnotetext{
9 [2021] EWOP 14.

${ }^{10}$ Para 19.
} 
significant risk of contracting the virus and of becoming seriously ill or dying if she does so. residence in a care home, age and health mean that there is a risk of her contracting and becoming seriously ill with Covid-19.

Instead, we submit that a case such as this, which concerns vaccines to vulnerable adults residing in care homes, should easily fall within a social worker's best interests decision-making expertise. A social worker's evidence would facilitate a move away from the focus on the balance of medical risks of the virus and the vaccine, which are relatively clear cut, towards the other facts that ought to be taken into account, including P's own wishes and feelings about the decision in question, as well as the implications for her care needs and everyday support. As noted above, there is evidence of the celebration of social workers' skills in relationship building and client centred practice, including in cases where the views or assessments of social workers may have conflicted with those of other professionals, including clinicians. It is for this reason that we argue that social work expertise is so important in best interests decision-making. In a case where a multidisciplinary mental health service sought authorisation for a care plan that amounted to a deprivation of liberty ${ }^{11}$ the judge singled out the social worker's experience, knowledge of the person and thorough care plan as exemplary samples of person centred professionalism. It is interesting to note that whilst the social worker's assessment is celebrated, so too is the detail and practicality of their chief output - the suggested care plan. While we think this rightly highlights social work expertise on best interests, in some senses, this approach to social worker expertise as being about service provision such as care planning reinforces its status as lower in the hierarchy of expertise. As Lindsey has explained, medical, particularly psychiatric experts, have more readily had their evidence accepted by the CoP as 'objective' and 'technical' expertise (Lindsey, 2020). Whereas social workers' evidence is relegated to more 'subjective' and 'experiential' in nature. While this may lead to social work evidence being praised and their

\footnotetext{
${ }^{11} A B$ (Inherent Jurisdiction Deprivation of Liberty) [2018] EWHC 3101 (Fam).
} 
appointment of independent experts on best interests, as we have advocated, it also undermines social work expertise in a wider sense within mental capacity law as social work is associated with less esteem than technical, scientific medical analysis.

This division of expertise between medical and social work can be witnessed in Buckinghamshire County Council $v R T^{12}$ which concerned the future care, accommodation and support provisions for a young man turning 18 . In this instance the court called for a Consultant Psychologist to assess the young man's capacity regarding his future care needs. This judgment was followed by evidence from a social worker who was asked to comment on her impressions of RT's functioning but, moreover, to provide assurances about the quality and appropriateness of the care provision on offer: ${ }^{13}$

He is provided with his own bedroom with an ensuite bathroom which has been adapted $\ldots$

In another case, $\operatorname{Re} P,^{14}$ which concerned a family wishing to move $\mathrm{P}$ to a family home in another region, the court sought assurances from the independent social worker that this care plan was feasible before ruling it to be in P's best interests. In this instance the independent social worker expressed doubt about the longevity of the proposed care plan given the extent of its reliance on a large number of family members to provide intimate care on a rota basis. These concerns were rejected by the court with suggestions that the social worker demonstrated limited faith in the commitment of family members and perhaps a limited cultural competence in failing to appreciate how this families' sense of duty towards each other would prevail. This critique of social worker's professional judgments is evident in other cases too, with, for example statements that restrictions

\footnotetext{
12 [2018] EWCOP 12.

${ }^{13}$ Para 25.

${ }^{14}$ [2017] EWCOP B26
} 
sought by the local authority social workers were not 'justifiable, proportionate or necessary'. ${ }^{15}$ Following these examples, it could be argued that the court are seeking assurances that the personalised safeguarding plans proposed will be feasible. However, by seeking assurances from the social work professionals in relation to best interest decisions and care planning, the responsibility for execution of the safeguarding plan is duly placed on social workers. In these instances, once the technical expertise has been shared by, for example, a medical professional, they are discharged of their duties, whereas the responsibility for overseeing the best interests decision and effective safeguarding remains with the appointed social worker within the local authority who has to oversee the implementation of what the court orders. While we recognise that social work evidence can be legitimately scrutinised by the court and we do not suggest that social work evidence should always be followed, it is important that social workers are seen as experts when it comes to best interests decision-making in welfare cases before the CoP. Their evidence is likely to reflect the realities of the provision of care and support on the ground and is rightly informed by their specialist expertise in supporting service users in everyday life.

\section{Conclusion}

There are clear challenges for social workers in working within the MCA and CoP frameworks, particularly where they struggle to articulate a specific technical expertise which fits the model of expert evidence required by the law. Despite the challenges for social workers in delineating a clear domain of expertise in mental capacity law, particularly when contrasted against the court appointed medical expert, we have highlighted cases where social work evidence has been adduced and received in positive terms. We recognise that social work expertise is less relied upon for technical expertise on mental capacity but is much more central to the question of what is in the person's best interests,

\footnotetext{
${ }^{15}$ SR v A Local Authority [2018] EWCOP 36, para 46.
} 
particularly in the domain of welfare cases and care planning. In light of this, social workers should feel more confident in asserting their evidence in these domains, not only as knowledge from experience of the person but as a legitimate form of expertise on which the courts ought to rely and even celebrate.

\section{References}

Brammer, A. (2012), "Inside the Court of Protection", The Journal of Adult Protection, Vol. 14 No. 6, pp. 297-301.

Braye, S. and Preston-Shoot, M. (2017), Learning from SARs: A Report for the London Adult Safeguarding Board, London Safeguarding Adults Board, London.

British Association of Social Workers (BASW). (2014), Code of Ethics, BASW Press, UK.

Clough, B. (2018), "New Legal Landscapes: (Re)Constructing the Boundaries of Mental Capacity Law", Medical Law Review, Vol. 26 No. 2, pp. 246-275.

Cooper, A. and Lousada, J. (2005) Borderline Welfare: Feeling and Fear of Feeling in Modern Welfare. Karnac Books, London.

Department for Constitutional Affairs. (2007), The Mental Capacity Act 2005: Code of Practice. Office of the Public Guardian, London

Dunn, M., Clare, I. C. \& Holland, A. J. (2008), "To Empower or to Protect? Constructing the 'Vulnerable Adult' in English Law and Public Policy", Legal Studies, Vol. 28 No. 2, pp. 234-253.

Harding, R. \& Taşcıoğlu, E. (2020), "Research Handbook on Gender, Sexuality and the Law", in Thats a bit of a minefield: supported decision making in intellectually disabled peoples intimate lives. Edward Elgar Publishing.

Hollomotz, A. (2011) Learning Difficulties and Sexual Vulnerability: A Social Approach. Jessica Kingsley Publishers, London. 
Jones, R. (2014), The Story of Baby P: Setting the Record Straight, 1st ed., Bristol University Press, Bristol.

Keeling, A. (2017) “Organising Objects': Adult Safeguarding Practice and Article 16 of the United Nations Convention on the Rights of Persons with Disabilities", International Journal of Law and Psychiatry, Vol. 53, pp. 77-87.

Kettle, M. (2018) “A Balancing Act: A Grounded Theory Study of the Professional Judgement of Child Protection Social Workers", Journal of Social Work Practice, Vol. 32 No. 2, pp. 219-231.

Kong, C. and Ruck Keene, A. (2018), Overcoming Challenges in the Mental Capacity Act 2005: Practical Guidance for Working with Complex Issues, Jessica Kingsley Publishers, London.

Lindsey, J. (2020), “Competing Professional Knowledge Claims About Mental Capacity in the Court of Protection", Medical Law Review, Vol. 28 No. 1, pp. 1-29.

Lindsey, J. (Forthcoming), "Best Interests and Relationality in Reproductive Healthcare", in Davey and Lindsey (Eds.) Grandparents and the Law: Rights and Relationships. Hart Publishing, Oxford.

Manthorpe, J., Rapaport, J. and Stanley, N. (2009), “Expertise and Experience: People with Experiences of Using Services and Carers' Views of the Mental Capacity Act 2005", British Journal of Social Work, Vol. 39 No. 5, pp. 884-900.

Ministry of Justice, (2020), “Family Court Statistics Quarterly: October to December 2020", available at: $\quad$ www.gov.uk/government/statistics/family-court-statistics-quarterly-october-todecember-2020 (accessed 14 June 2021).

Munro, E. (2011), A Child-Centred System, TSO, Norwich.

Murrell, A. \& McCalla, L. (2015) “Assessing Decision-making Capacity: The Interpretation and Implementation of the Mental Capacity Act 2005 Amongst Social Care Professionals", Practice, Vol. 28 No. 1, pp. 1-16.

Preston-Shoot, M. et al. (2020), Analysis of Safeguarding Adult Reviews April 2017 - March 2019: Findings for Sector-Led Improvement. Local Government Association Press. London, available at: 
www.local.gov.uk/sites/default/files/documents/National\%20SAR\%20Analysis\%20Final\%20 Report\%20WEB.pdf (accessed 4 August 2021).

Preston-Shoot, M. (2021), “MS: A Safeguarding Adults Review, City and Hackney Safeguarding Adults Board", available at: www.drive.google.com/file/d/1Uttdi0Z76iWbt0txvlhtg8yliNL21djg/view (accessed 14 June 2021).

Series, L., Mercer, A., Walbridge, A., Mobbs, K., Fennell, P., Doughty, J. and Clements, L. (2015) Use of the Court of Protection's Welfare Jurisdiction by Supervisory Bodies in England and Wales. Cardiff University Press, Cardiff.

Shoesmith, S. (2016), Learning from Baby P: The Politics of Blame, Fear and Denial. Jessica Kingsley Publishers, London.

Unison. (2015), Social Work, the Courts \& Consequences of Transparency. Report of a Unison Survey of Social Work Practitioners, available at: www.unison.org.uk.

Weston, J. (2020) "Managing Mental Incapacity in the 20th century: A History of the Court of Protection of England \& Wales", International Journal of Law and Psychiatry, Vol. 68 No. 1. 